\title{
CUSTOMER SATISFACTION WITH QUALITY \\ OF PRODUCTS OF FOOD BUSINESS
}

\section{Petr Suchánek, Jiří Richter, Maria Králová*}

\begin{abstract}
This article is a part of a specific research output called Quality Influence on the Performance and Competitiveness of the Company. One of the research phases is elaborated in this article; its subject is measuring customer satisfaction with the quality of food products companies in the Czech Republic. This article aim is to determine the level of customer satisfaction with the quality of food production enterprises. The partial aim of the article is to identify factors that have the greatest influence on the customer satisfaction. The research confirms close relations between customers' quality perception, their satisfaction and the level of fulfilment of their demands.
\end{abstract}

Keywords: customer satisfaction, quality, food industry, quality management, company performance, competition, repurchase, customer expectation

JEL Classification: L15, L6

\section{Introduction}

This article is the specific output of a Research Project entitled "The Influence of Quality on the Performance and Competitiveness of Companies" (No. 0738/2012). The research consists of several basic steps, the first one being the measurement of customer satisfaction with the products produced by the companies in question (as per the subject matter of this article, see below). The second step consists in the self-evaluation by the respective companies of the quality of their own products, while the third step is essentially a comparison of results, so that any differences can be identified and addressed. Subsequently, it is necessary to identify quality management methods applied in the companies and the resulting performance. The outcomes of individual steps were compared and contrasted to enable conclusions regarding the actual influence of customer satisfaction on product quality, the influence of quality management on product quality and the influence of customer satisfaction and quality management on company performance. All of the above is expected to result in the improvement of managerial activities (or management per se) to ensure the long-term excellence of companies.

Considering the fact that the respondents (customers) need to be familiar with the products in question (and in order to have as many respondents as possible) the research

* Petr Suchánek, Faculty of Economics and Administration, Department of Corporate Economy,

Department of Applied Mathematics and Computer Science, Masaryk University, Brno,

Czech Republic (suchy@econ.muni.cz);

Jiří Richter, Faculty of Economics and Administration, Department of Corporate Economy,

Department of Applied Mathematics and Computer Science, Masaryk University, Brno,

Czech Republic (jiri.a.richter@mail.muni.cz);

Maria Králová. Faculty of Economics and Administration, Department of Corporate Economy,

Department of Applied Mathematics and Computer Science, Masaryk University, Brno,

Czech Republic (kralova@econ.muni.cz). 
was focussed on food industry companies headquartered in the Czech Republic. Thanks to the legislative instruments applied to ensure quality management in this industry, the companies in question are indeed concerned with the quality control and sufficient amount of materials and data can be collected for research. That said, comparative research can be carried out in the future with regard to companies that do not have quality management systems in place, or companies from other industry sectors.

Therefore, the subject matter of this article is the measurement of customer satisfaction with the quality of products from the foodstuffs industry in the Czech Republic, although the research sample does not cover the Czech customers in general, it represents especially the demographic group of students (see below). The aim of the article is to determine the level of satisfaction with the quality of foodstuff production and to identify factors that affect satisfaction (including any correlations between the former and the latter).

\section{Theoretical Background}

Quality is defined as a zero error rate, i.e. the ability to produce a perfect product on the first try (Parasuraman et al., 1985). Crosby defines quality as the producer's ability to meet expectations (Crosby, 1979 quoted in Parasuraman et al., 1985). This definition of quality is the core of the definition contained in the ISO 9001 standard (cf. ČNN EN ISO 9001, 2010). As far as the customer's (consumer's) point of view is concerned, quality can be defined as the quality perceived upon the basis of the consumer's decision on the overall excellence or superiority of the product (Zeithaml, 1988). All definitions mentioned above apply to the quality of a product, which is consistent with the focus of the research into the foodstuffs industry.

Customer satisfaction can be defined with the use of two basic concepts: transaction based satisfaction and cumulative satisfaction. Transaction based satisfaction is based on the evaluation of a specific purchase once the selection has been made and the product has been purchased. On the other hand, cumulative satisfaction is based on the overall experience after the purchase and use of the product/service over a certain period of time (Anderson, Formelo, Lehmann, 1994). With respect to the definitions above, the former is more suitable for the authors of this article, since their research is focussed on customer satisfaction with one particular product. Furthermore, satisfaction can be defined and measured as consumer ratings of specific attributes (Gómez et al., 2004) and can be defined as a comparison of previously held expectations with perceived product or service performance (Homburg et al., 2005; Anderson et al., 1994). With respect to the focus of the paper on company's product quality, we have defined customer satisfaction as a subjective reflection of this quality.

The quality can be regarded as the result of a subjective process whereby the customer compares their ideas (or expectations) with the reality. Moreover, the higher product quality does not necessarily equal a higher level of customer satisfaction (Oliver, 1980). We can agree with this statement, the exception being that higher customer satisfaction automatically means higher product quality (as perceived by a specific consumer). She also mentions key factors which affect customer satisfaction and which can be used to measure customer satisfaction. These factors include: product, price, services, distribution and image (Zamazalová, 2008). 
However, if customer satisfaction is predetermined by product quality and if, at the same time, this level of satisfaction affects product quality, a certain factor affects quality and vice versa. This is, however, not a problem in the case of dynamic perception of satisfaction and quality, i.e. if one perceives quality and customer satisfaction as a process (cf. Deming, 1982). Consequently, technical and moral quality affect customer satisfaction, while the manufacturer can determine the level of customer satisfaction and respond via product innovations to ensure even greater customer satisfaction. By doing so, the manufacturer improves product quality and the circle is complete.

The aforementioned definitions suggest that customer satisfaction is determined by the level of the fulfilment of expectations by the product. Therefore, the overall product quality level is based on the degree to which expectations have been met. Hence, customer satisfaction is the main factor (and criterion) of product quality. It is possible to objectively measure the level of satisfaction via the contributing factors. The text below defines quality as the idea of quality perceived by customers through the expression of satisfaction. To ensure that a product meets customer expectations, the company must be able to manufacture it. This ability is determined, affected and improved by the overall quality management on the one hand and the familiarity with customer expectations on the other hand.

It would seem that it is not a problem to produce a perfect product (in technical terms). The problem is to collect information on customer needs to ensure that the resulting product meets all of them. Hence, production per se is not the problem; companies need to address the issue of communication with customers, i.e. marketing and quality management in the broader sense.

\section{Research Methodology}

\subsection{Theoretical concept}

Research methods were based on the authors' previous work (cf. Suchánek, 2012 and Suchánek, Špalek, 2012). Generally speaking, the goal of the research is to recognize the correlation between quality, as managed by companies, and quality, as perceived by consumers, as well as to measure the dependence between quality and economic performance of companies. The primary goal of the research is to give producers of foodstuffs the necessary information based on which they will be able to optimise their internal QM processes and increase their economic performance and competitiveness.

The goal of the research into customer satisfaction is the understanding of consumer behaviour (shopping habits) and the description of the correlation between Czech consumers' satisfaction and the quality of foodstuffs, including the effects on the performance of the producers. Within the framework of questionnaire-based surveys, primary data can be collected on Czech consumers' satisfaction with foodstuffs and hypotheses can be formulated to address the key factors that influence satisfaction and the subjective perception of quality. Thanks to the relatively high number of respondents, the authors were able to objectively compare selected product ranges with regard to their moral quality and the classification of companies based on the results of their product ranges. Using conventional statistical methods, the significance of quality factors can be assessed with regard to overall customer satisfaction. Based on this assessment, the effectiveness of the manufacturer's management processes can be determined. 
Two basic research questions can be asked: Which factors are most important with regard to customer satisfaction? and Why do consumers think certain product ranges, brands or companies offer better quality than their competitors? The combination of knowledge from individual stages of the research can answer the question: How should the product quality management process be organised to ensure maximum customer satisfaction and to maximise economic performance (profitability) of the company?

Based on previous research and the study of literature on this topic, it was deemed appropriate to explain the correlation between customer satisfaction, product quality and customer expectations, all of which may very well be the most important factors affecting product quality (as compared with competing products), as well as the willingness to purchase the same product again and recommend the purchase to other prospective customers. Therefore, a theoretical product quality model has been devised where customer satisfaction is the key to success and financial excellence of the manufacturer; the said customer satisfaction is influenced by their expectations (the level of the meeting of expectations) and, consequently, product quality. The quality of the specific purchased product is compared with that of competing products (based upon the ability to meet customer expectations) and is reflected in customer loyalty (repeat purchase) and their willingness to recommend the product to other prospective customers. The links and relations referred to above are shown in Figure 1. The possibility, that customers' satisfaction (expectations) is influenced by not mentioned factors is taken into account, yet not elaborated in the article. The large amount of all the factors interfering were not able to be elaborated within one research, thus we have focussed on a segment expressed by introduced model. To prove the relationships between variables shown in Figure 1, following hypotheses were formulated:

- H1: The more customer expectations are met, the happier the customer is.

- H2: The happier the customer, the more likely the product will be deemed superior to other products.

- $\quad$ H3: The more customer expectations are met, the more likely the product will be deemed superior to other products.

- H4: The better the quality of a product, as perceived by consumers, the more likely it will be recommended to prospective consumers.

- $\quad$ H5: The better the quality of a product, as perceived by consumers, the more likely the consumers will purchase the product again.

- H6: The more satisfied the customer is, the more likely they will be willing to recommend products to other people.

- H7: The more satisfied the customer is, the more likely they will purchase the product again.

- H8: The more satisfied the customer is, the more customers think that its quality exceeds the quality of competing products.

- H9: The better a product is thought to be, the more customers think that its quality exceeds the quality of competing products.

- H10: The more customer expectations are met, the more likely the product will be preferred to other products in terms of quality. 


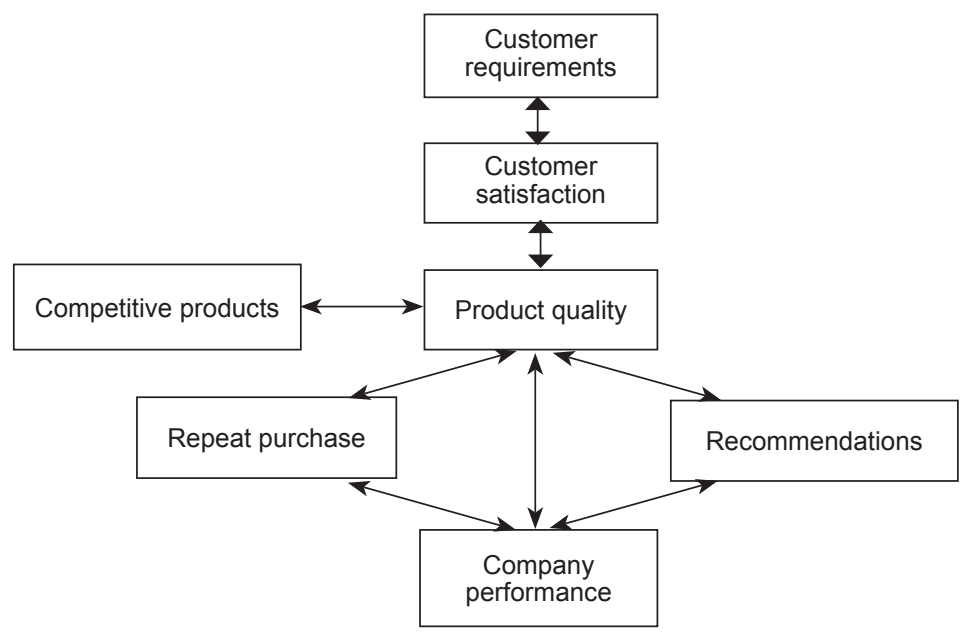

Source: Authors.

Although the presented relationships may seem to be obvious, there is no reliable empirical evidence proving these links in current state of Czech environment. The objective of the hypotheses testing is to establish a validated and functional basis for further quality research. The comparison of the model with the current approaches to customer perceived quality abroad is the objective of further research.

\subsection{Research methods used}

A questionnaire was devised for the research into customer satisfaction with the products of selected manufacturers. The respondents filled out the questionnaire themselves. Its introduction included identification of the product and product range, while the conclusion included the identification of the respondent. The main part of the questionnaire, focussed on customer satisfaction, contained 13 questions, six of which were close-ended questions (10-point scale), five were semi-open questions and two were yes-or-no questions. One of the latter was divided into semi-open sub-questions.

The results were analysed via descriptive statistics tools, e.g. absolute and relative frequency, weighted average and median. The Pearson product-moment correlation coefficient and the coefficient of determination were used for hypothesis testing. All hypotheses were tested at the significance level of $p=0.05$. The normality of pairs of tested variables was tested as well. All statistical calculations were made with the use of special software STATISTICA.

\section{Specification of Research Samples}

Two research samples were set up for the purpose of the research: companies and respondents who evaluated the quality of products (sample). Companies from the food industry were selected to participate in the research, since these products are generally well-known and widely available. Due to the necessity to evaluate company performance, the sample 
had to include only limited liability companies and joint stock companies, upon the basis of their obligation to disclose their financial results in the form of balance sheets and PL statements or annual reports. Furthermore, the research was focussed on companies which are known to manufacture their products in the Czech Republic, to ensure the transfer of the influence of corporate management to manufacturing and distribution and, therefore, to prove the level of influence of the quality of a Czech-made product on the performance of the company (founded in, and managed from, the Czech Republic).

The basic set of foodstuff producers according to business activity (dominating activity pursuant to CZ-NACE - category 10 Manufacture of food products and 11 Manufacture of beverages) and legal status (joint stock company and limited liability company) includes 4,033 companies. Due to the fact that the research was focussed on quality management, it was necessary to eliminate companies concerned with the resale of products manufactured by their foreign parent company and companies acting as sales representations in the Czech Republic. A total of 458 companies were identified via the CPV classification criterion. Excluded from the research were business entities that do not report financial performance data on their own and enterprises dealing in semi-finished products used for industrial processing rather than end-user consumption. The resulting set was represented by a total of 24 companies. In terms of legal status, 33\% were limited liability companies and $67 \%$ were joint stock companies. It may seem at first that this sample is quite small, but in fact the research covered 55 product ranges, or 59 products. The basic criterion of company size is the number of employees: $21 \%$ of companies are small enterprises (fewer than 50 employees); $63 \%$ are medium-sized enterprises (50 to 249 employees) and 17\% are large enterprises (more than 250 employees.

The second research sample was represented by customers of the companies from the first sample. Familiarity with the products in question was a condition of participation in the research. A total of 13,683 properly and fully completed questionnaires were returned for further processing. The male-female ratio was almost balanced $(50.91 \%$ men and $49.09 \%$ women). The age groups of the respondents were represented as follows: the largest group was represented by persons aged 16 to 25 (62.31\%), followed by smaller groups of older respondents (as anticipated, the older the respondents, the smaller the groups): 26-35 (12.14\%); 36-45 (9.87\%); 46-55 (9.42\%) and 55+ (4.89\%). The age group 10-15 was considered marginal $(1.37 \%)$ which is a plus for the research, since these respondents usually do not demonstrate shopping habits of their own and cannot make qualified decisions with regard to product selection. In terms of the respondents' occupations, they were students $(60.07 \%)$, people employed in the private sector $(17.62 \%)$ and people employed in the public sector $(10.31 \%)$. Approximately $12 \%$ of the sample is represented by the total of business persons $(5.72 \%)$, unemployed $(2.43 \%)$ and pensioners $(3.84 \%)$.

As follows from the sociodemographic description, the research sample is not representative for Czech population due to high representation of young (age 16-25) students (60.07\%). Regarding their mainly high-school and university education the results of this study may be applied mainly on population of knowledgeable customers, the students and their relatives.

\section{Results of Customer Satisfaction with Product Quality}

The results of customer satisfaction with food product quality are summarised for individual companies: satisfaction surveys for individual products were combined into product ranges and, consequently, the results for the product ranges were combined for the entire 
company. Data synthesis was carried out via averaging, in order to ensure the objectivity and legitimacy of the results.

Table 1 lists the results for scaled questions for the entire set of the foodstuff producers used in the research as arithmetical average. Requirements reflects the level of satisfaction with meeting expectations (value on scale 1 minimum meeting of requirements, value 10 maximum meeting of requirements); Quality reflects the level of satisfaction with the quality of the product (value on scale 1 minimum meeting of expectations, value 10 maximum meeting of expectations); Satisfaction reflects the extent to which the respondents were satisfied with the product (value on scale 1 minimum satisfaction, value 10 satisfaction); Repeat purchase reflects the willingness of the respondents to buy the same product again (value on scale 1 definitely yes, value 10 certainly no); Recommendation reflects the customers' willingness to recommend the product to other prospective customers (value on scale 1 definitely yes, value 10 certainly no) and Comparison reflects the product's position on the market, as compared with that of competing products (value on scale 1 product is significantly worse, value 10 product is significantly better).

Table 1 | Customer Satisfaction Evaluation via Scaled Questions (in \%)

\begin{tabular}{|l|c|c|c|c|c|c|c|c|c|c|}
\hline & $\mathbf{1}$ & $\mathbf{2}$ & $\mathbf{3}$ & $\mathbf{4}$ & $\mathbf{5}$ & $\mathbf{6}$ & $\mathbf{7}$ & $\mathbf{8}$ & $\mathbf{9}$ & $\mathbf{1 0}$ \\
\hline Requirements & 0.87 & 1.55 & 2.62 & 3.81 & 7.43 & 10.93 & 16.62 & 22.51 & 19.24 & 14.43 \\
\hline Quality & 0.45 & 1.12 & 2.37 & 4.28 & 11.41 & 13.67 & 18.81 & 20.76 & 16.89 & 10.23 \\
\hline Satisfaction & 0.82 & 1.22 & 2.05 & 4.23 & 8.22 & 11.27 & 15.49 & 18.25 & 25.06 & 13.38 \\
\hline Repurchase & 26.49 & 16.09 & 14.38 & 10.93 & 8.80 & 8.24 & 5.17 & 4.38 & 2.76 & 2.55 \\
\hline Recommendation & 24.76 & 17.12 & 15.08 & 9.81 & 10.35 & 8.44 & 4.91 & 4.05 & 1.87 & 3.59 \\
\hline Comparison & 1.02 & 2.14 & 4.61 & 6.79 & 12.40 & 16.34 & 16.41 & 17.53 & 14.17 & 8.55 \\
\hline
\end{tabular}

Source: Authors' own calculations.

The results in the table show that satisfaction with meeting expectations was above average. On the other hand, we can see that only $14.43 \%$ of respondents were absolutely satisfied and that 8 was the most frequent rating. By contrast, the minimum percentage of respondents was absolutely dissatisfied.

Product quality was rated similarly to the rating of meeting expectations. The results prove that most respondents rated product quality as above average. On the other hand, only $10.23 \%$ of respondents expressed maximum satisfaction; the most common rating was 8 . By contrast, very few respondents were dissatisfied.

Customer satisfaction was evaluated the same way. The results show that most respondents rated it as above average. A total of $13.38 \%$ of respondents expressed maximum satisfaction, with 9 being the most common rating. By contrast, very few respondents expressed low satisfaction levels.

The question pertaining to customer satisfaction had a sub-question (if the respondent gave a rating of 1 to 8 , which was the case in $61.56 \%$ of respondents) covering the factors of dissatisfaction, namely product level, flexibility, prices and other. The most common response was product level (45.87\%), followed by other $(23.99 \%)$, prices $(21.40 \%)$ and finally flexibility $(8.74 \%)$. 
Figure 2 | Customer Satisfaction Evaluation via Scaled Questions
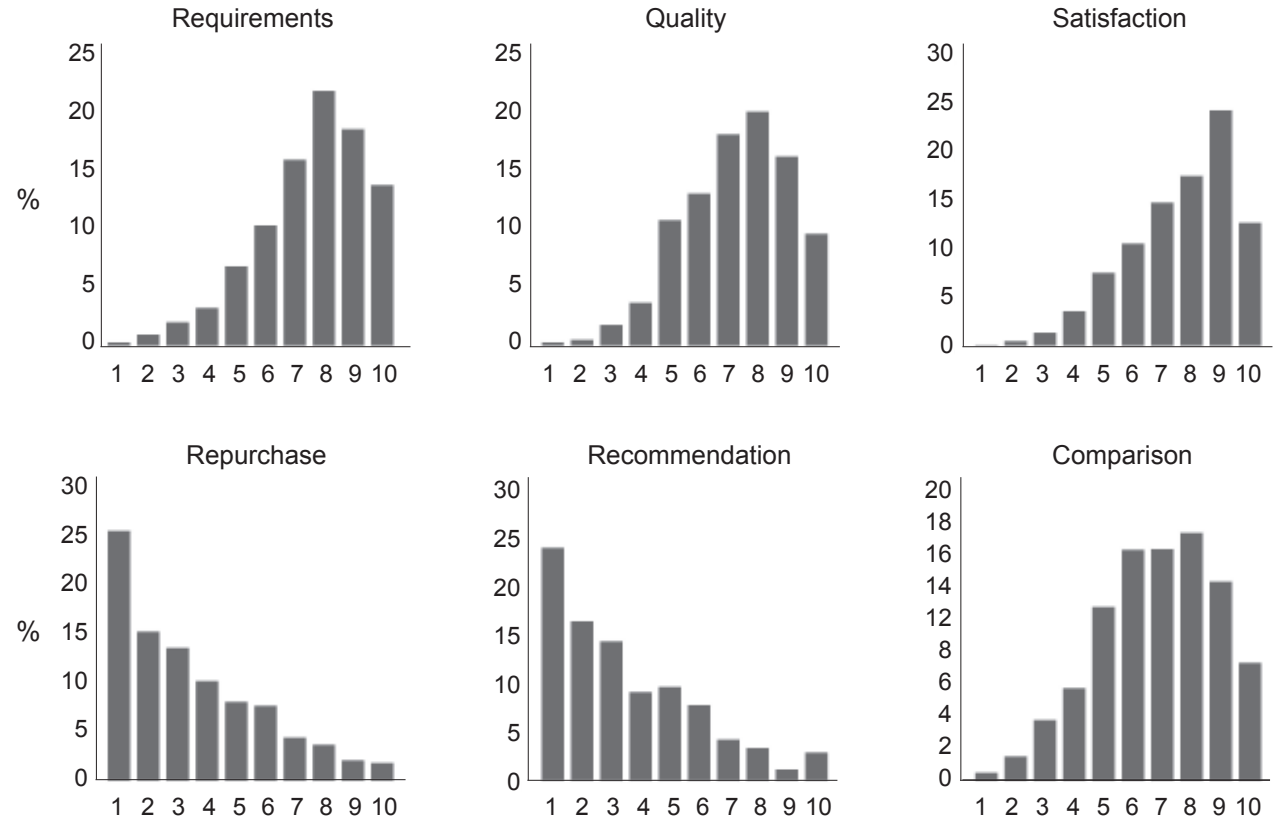

Source: Authors' own calculations.

This question had another sub-question pertinent to customer satisfaction surveys (if and when conducted by the manufacturer or vendor). Most respondents stated that no customer satisfaction survey had ever been conducted $(93.88 \%)$, i.e. only $6.11 \%$ of respondents had been approached with a customer survey.

Table 2 | Methods and Frequency of Customer Satisfaction Surveys (in \%)

\begin{tabular}{|l|c|l|c|}
\hline Survey method & Relative frequency & Survey frequency & Relative frequency \\
\hline Questionnaire & 29.22 & Daily & 0.00 \\
\hline Interview & 33.31 & Weekly & 0.30 \\
\hline Telephone & 2.84 & Monthly & 1.34 \\
\hline Handover protocol & 0.90 & Quarterly & 2.20 \\
\hline Internet & 15.41 & Annually & 11.01 \\
\hline Other & 14.31 & Upon product handover & 36.01 \\
\hline \multirow{2}{*}{ No answer } & 4.01 & Irregularly & 36.68 \\
\hline \multirow{2}{*}{} & & Other & 8.45 \\
\cline { 2 - 4 } & & No answer & 4.01 \\
\hline
\end{tabular}

Source: Authors' own calculations. 
Table 2 shows the frequency and methods of these surveys. The results show that interviews and questionnaires were the most common methods. By contrast, the Internet was used much less often, as was telephone. As for the frequency of these surveys, most of them were irregular and upon handover of the product.

As for the question whether or not the respondents were willing to purchase the product again (Table 1), the scale ranged from 1 (definitely yes), with the neutral 5 (not sure), to 10 (definitely not). The results show that most respondents were willing to purchase the product again, with $26.49 \%$ of them definitely (this being the most common answer). By contrast, very few respondents will not buy the product anymore.

In the case of the comparison of the products with competing products (Table 1), the scale ranged from 1 (very bad), with the neutral 5 (roughly the same), to 10 (excellent). The results prove that most respondents rate the product as above average, but not excellent. The most common rating on the aforementioned scale was 8 ; only $8.55 \%$ of respondents gave 10 . By contrast, very few respondents thought the product was very bad.

Table 3 | Product Strengths and Weaknesses (in \%)

\begin{tabular}{|l|c|l|c|}
\hline Product strengths & Relative frequency & Product weaknesses & Relative frequency \\
\hline Tradition & 22.75 & Tradition & 8.22 \\
\hline Quality & 31.07 & Quality & 21.45 \\
\hline Flexibility & 6.30 & Flexibility & 8.53 \\
\hline Price & 22.30 & Price & 25.05 \\
\hline Location & 6.55 & Location & 8.63 \\
\hline Other & 11.04 & Other & 28.13 \\
\hline
\end{tabular}

Source: Authors' own calculations.

Table 3 lists strengths and weaknesses of products as perceived by the respondents. The results suggest that the three most frequently named strengths were quality, tradition and price. On the other hand, most respondents do not consider flexibility and location to be product strengths. As for weaknesses, most respondents listed price and quality. By contrast, tradition, flexibility and location were not seen as weaknesses by many respondents. However, it is evident that many respondents see other weaknesses which were not specifically named and are listed as Other.

Table 4 provides an overview of the period of use and frequency of use of the products in question. The results show that most respondents use their products for more than three years and between 1 and 3 years. A significant percentage of respondents do not even know how long it has been since they bought the product. On the other hand, only $5.31 \%$ of respondents have had their product for less than one month. The respondents typically use their product twice to three times a year or twice to three times a month or once a month. 
Table 4 | Period of Use and Frequency of Use of the Product (in \%)

\begin{tabular}{|l|c|l|c|}
\hline Period of use & Relative frequency & \multicolumn{1}{|c|}{ Frequency of use } & Relative frequency \\
\hline Less than one month & 5.31 & On a daily basis & 5.46 \\
\hline 1 to 6 months & 11.91 & Once a week & 12.68 \\
\hline 6 months to 1 year & 13.19 & 2 to 3 times a month & 15.13 \\
\hline 1 to 3 years & 21.32 & Once a month & 14.56 \\
\hline More than 3 years & 28.52 & Every 2 to 3 months & 14.13 \\
\hline I am not sure how long & 15.24 & 2 to 3 times a year & 18.36 \\
\hline I have never used it & 1.24 & I am not sure how often & 10.01 \\
\hline Other & 2.96 & Other & 9.61 \\
\hline
\end{tabular}

Source: Authors' own calculations.

\section{Model Testing Results}

Within the framework of model testing, individual Hypotheses H1-H10 listed below were tested. The tests based on Pearson correlation coefficients were performed at the significance level $\alpha=5 \%$ and all of them were statistically significant ${ }^{1}$. Not only that, all the effect sizes (represented by coefficients of determination derived from Pearson product-moment correlation coefficients) related to particular tests were of high interest in the considered H1-H10 context.

As the tests based on Pearson correlation coefficients assume bivariate normality and consequently linear relationship between considered pair of variables, this linearity was for all pairs of variables assessed by scatterplots ${ }^{2}$ which showed clear linear relationship in 6 out of 10 pairs of variables. See the following picture demonstrating "linearity":

The "worst" scatterplot in terms of linearity where the relationship was not clearly linear but still monotonous (Figure 4).

1 The alternative hypotheses in the test procedure were represented by particular research Hypotheses $\mathrm{H} 1-\mathrm{H} 10$. As the null hypotheses were rejected in favour of alternative ones, the statements in research hypotheses were proved at significance levels $\alpha=5 \%$.

2 The sample statistics, test statistics and related p-values are calculated from raw data, whereas graphs in Figure 3 and 4 are based on slightly "shifted" data. As the variables were measured on the 10 point scale, repeated measurements would have overlapped. For that reason to any of these variables randomly generated variables following normal distribution with standard deviation $=0.5$ were added. 
Figure 3 | Linear Relationship Demonstration

Scatterplot Evaluation vs. Comparison

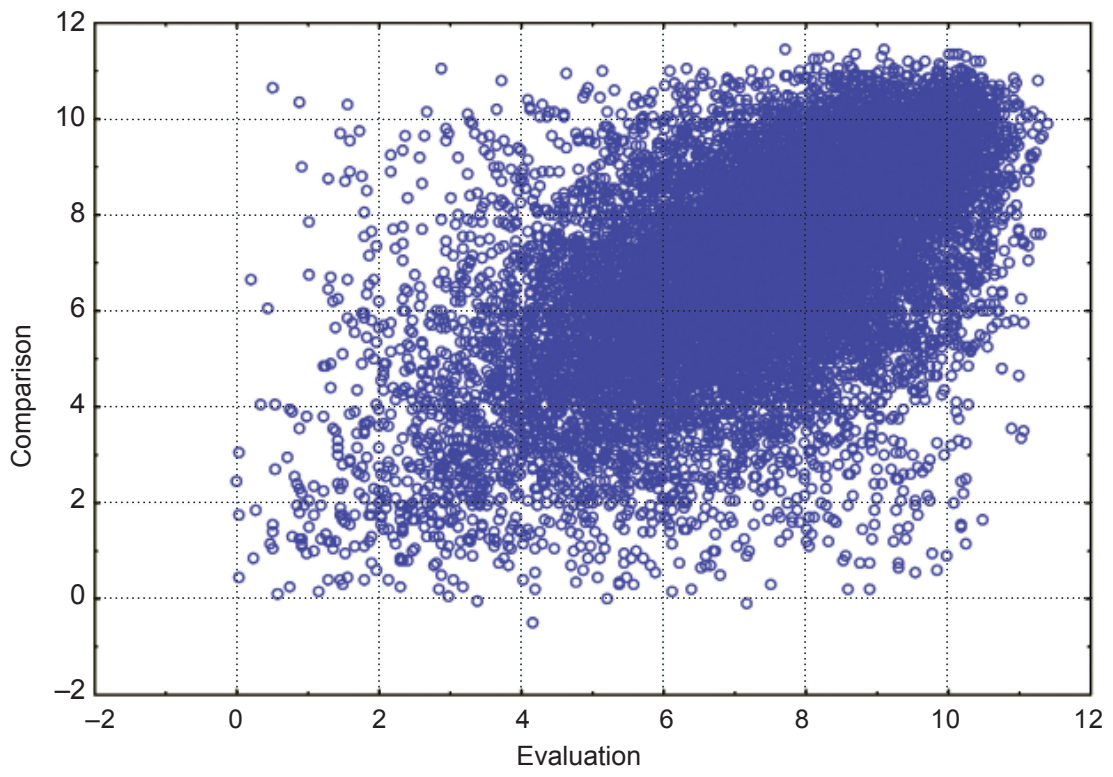

Source: Authors.

Figure 4 | Worst Scatterplot in Terms of Linearity

Scatterplot Evaluation vs. Repurchase

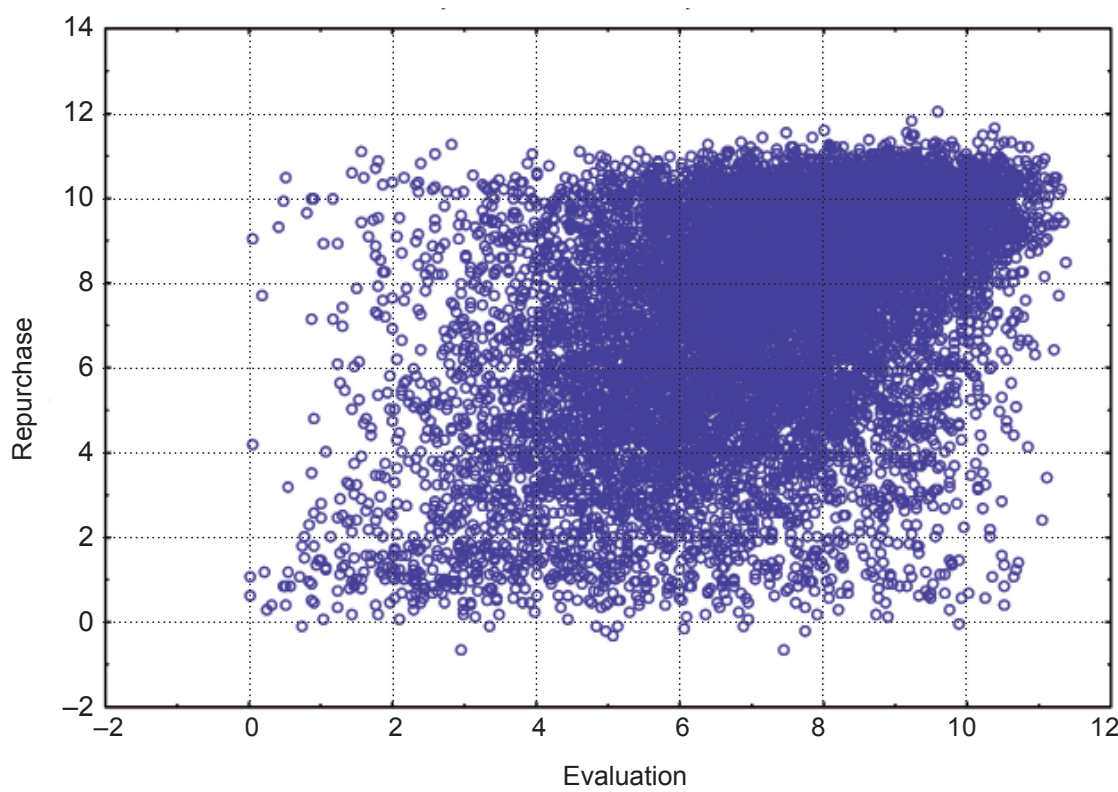

Source: Authors. 
(There were four pairs of variables where the linear relationship was not so clear, the upper displayed picture represents the "worst" one.) In this pair the sample Pearson correlation coefficient was 0.514483 , whereas the sample Spearman ${ }^{3}$ correlation coefficient was 0.515265 . As there is no difference in interpretation of results (using either Pearson or Spearman correlation coefficients or p-values of related tests) and for the sake of a coherence of the list of all hypothesis we decided to perform only Pearson correlation coefficients.

The results of individual tests are summarised below.

Table 5 | Results of Individual Tests

\begin{tabular}{|l|c|c|c|c|}
\hline Hypothesis & $\begin{array}{c}\text { Pearson product-moment } \\
\text { correlation coefficient }\end{array}$ & $\begin{array}{c}\text { Coefficient } \\
\text { of determination (\%) }\end{array}$ & p-value & Result \\
\hline H1 & 0.79 & 62.56 & 0.00 & Proved \\
\hline H2 & 0.67 & 46.15 & 0.00 & Proved \\
\hline H3 & 0.67 & 45.59 & 0.00 & Proved \\
\hline H4 & 0.55 & 31.27 & 0.00 & Proved \\
\hline H5 & 0.51 & 26.47 & 0.00 & Proved \\
\hline H6 & 0.66 & 44.63 & 0.00 & Proved \\
\hline H7 & 0.64 & 41.61 & 0.00 & Proved \\
\hline H8 & 0.63 & 40.40 & 0.00 & Proved \\
\hline H9 & 0.69 & 35.77 & 0.00 & Proved \\
\hline H10 & 0.61 & 38.35 & 0.00 & Proved \\
\hline
\end{tabular}

Source: Authors' own calculations.

Based upon the results of the hypotheses the model introduced above can be modified, so that customer expectations are reflected in their satisfaction as well as in product quality, thereby forming one entity based on which the company (product) and its current performance are compared with its competitors. Furthermore, customer satisfaction and product quality are reflected in the willingness to purchase the product again and to recommend the purchase to other (new) customers (i.e. to acquire new customers) which establishes a correlation with the company's future performance. The modified version of the model is provided in Figure 5.

Therefore, if the level of the meeting of expectations determines the level of satisfaction and product quality, correlations with the competition and the current performance of the company can be addressed. Based on this analysis, the competitiveness of the product and the company can also be assessed. It is also possible to estimate the rate of customer

3 Spearman correlation coefficient represents an appropriate measure of association for non-linear but still monotonous relationship between two variables. 
loyalty and the level of new customer acquisition and, based on this estimation, estimate the company's future performance.

It is interesting that quality is not perceived independently in relation to the product, or over time, but rather in relation to competing products. Quality perceived by the customer is a largely subjective phenomenon and it seems that the customer can be convinced (at least partially) that a product is of good quality.

Figure 5 | Modified Product Quality Model

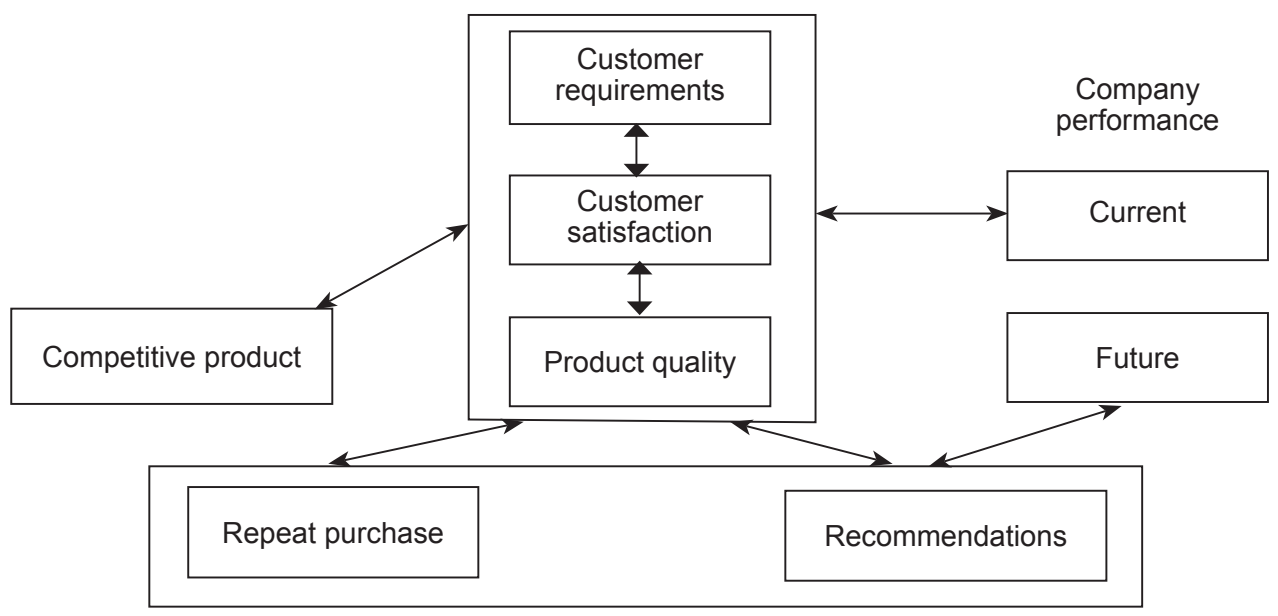

Source: Authors.

\section{Discussion}

Based on a comparison of the evaluation of product quality and the meeting of expectations, it is evident that the ratings given by the respondents are similar and relatively high. It suggests that the products included in the research are of top quality (cf. Hypothesis H3). By contrast, we can see that product quality was never rated as the maximum achievable quality (the same applies to the meeting of customers' expectations). The most common rating was 8 . Therefore, we can conclude that the most common level of product quality and the level of the meeting of expectations was 8 . This finding is consistent with the fact that the vast majority of respondents have never had to return the product or file a complaint on the grounds of the product being defective.

Considering the fact that product quality is defined by the level of the meeting of expectations, we can expect that the level of the meeting of expectations should be the same as product quality perceived by the customer. Despite the fact that these two values are nearly equal, we cannot ignore the fact that the issue of quality is rated slightly lower than the level of the meeting of expectations. It would seem that the perception of moral quality is significantly affected by another factor(-s), in addition to the level of the meeting of expectations. This opinion can be supported by our finding that the level of customer satisfaction is higher than the level of product quality, since the most common rating was 9. At the same time, the level of satisfaction is comparable with, or somewhat higher than, 
the level of the meeting of expectations. Hence, it is evident that customer satisfaction is closely related to product quality (cf. Hypothesis H2) and the level of customer expectations (cf. Hypothesis H1). At the same time, customer satisfaction appears to be significantly affected by another factor (factors), in addition to the level of the meeting of expectations.

Price can be the factor mentioned above, since it is listed as one of the factors of negative influence. At the same time, a lower level of customer satisfaction is caused by product level which is closely related to product quality and the meeting of customer expectations. Therefore, it is obvious that the respondents rated the quality of the foodstuffs included in the research as lower, i.e. they were aware of the imperfections in terms of product quality.

More than $50 \%$ of respondents are willing to purchase the product again (more than $25 \%$ are certain), which may be due to the fact that the products in question are foodstuffs, some of which are consumed on a daily basis. However, this assumption is not backed by the values pertinent to the frequency of use.

On the other hand, it is evident that many respondents would be willing to recommend the purchase of the products to other customers. We can conclude that they truly affirm the top quality of the product (cf. Hypothesis H4), as well as the high level of satisfaction (cf. Hypothesis H6), which includes satisfaction with the meeting of expectations. On the other hand, it is evident that the products included in the research still need some improvement because the respondents' ratings were only slightly above average. This may be the reason for lower rating of product quality (cf. Hypothesis H9). Notwithstanding the fact that most respondents consume the products in the long term, it is obvious that they are familiar with the products and they are also aware of the existence of alternatives to the product they use.

It is evident that product quality is an ambivalent issue: it is the most commonly named strength and, at the same time, one of the most commonly named weaknesses. The research results show that the respondents perceived the issue of pricing as a factor of its own, i.e. separately from quality. This may be the reason for the difference between customer satisfaction with a product and the moral quality as perceived by respondents. In addition, it is good to know that prices, albeit dominant, are not the only factor in the decision-making processes on the part of consumers, as quality is also considered as a key factor.

Of particular importance is the low influence of product flexibility and location on the consumers' decision-making processes, as these factors are neither strengths nor weaknesses. We can assume that the lack of interest in product flexibility is caused by accessibility of products combined with temporary consumption. The consumers know these products very well and have no reason to switch to competing products (after all, they satisfy the consumers' needs just fine). It may be caused by conservative behaviour on the part of Czech consumers. A sufficient product portfolio (and the resulting competition) and selection options may be another reason thanks to which customers become aware of the flexibility of the market as such which, according to them, is nothing extraordinary.

From this point of view, product flexibility may be understood as the situation in the market segment as such, whereas the respective company's product offer may be incomprehensible to customers. It may be related to the distribution method, where products are not distributed by individual manufacturers but by vendors who tend to change the portfolio offered by individual companies and combine various products into a new portfolio of their own. With respect to the aforesaid, the fact that customers are used to certain product portfolios and accessibility (in terms of localization) of products may also play its role. It may be interesting to conduct a research into customer behaviour in 
response to restrictions of product portfolios or accessibility) of products and whether or not the significance of these factors play any role with regard to strengths and weaknesses.

Considering the fact that the vast majority of respondents were not asked about their satisfaction with the product, we can assume that most foodstuff manufacturers do not measure customer satisfaction. Should this hypothesis be confirmed, it will probably be the main reason for lower customer satisfaction with products and the lower quality of products as such. It is going to be very complicated to change this situation (i.e. to improve product quality). In that case no improvement in performance should be expected from these companies.

This problem is further worsened by the finding that customer satisfaction is not measured systematically. Instead, it is a random process and if any company does have a schedule of some sort, customer satisfaction surveys are conducted infrequently, e.g. once a year. In addition, it is evident that only traditional methods of measuring customer satisfaction are used (i.e. questionnaires and interviews), while modern day media are used rarely. The serious problem is that the information on customer satisfaction is not provided to the manufacturer, as it is retained by the middle chain link (i.e. the vendor) which conducts the customer satisfaction survey (usually directly at the customer).

These findings are even more interesting in the light of the results of the research conducted in 2012 by the author of this article among foodstuff producers (cf. Suchánek, 2012). Despite the fact that the two research samples of companies (products) are not identical (they are $80 \%$ identical) and no strong conclusions can be derived from them, the comparison of the two research projects does deserve some contemplation. The former suggests that foodstuff producers do measure customer satisfaction and monitor the customers' wishes and then incorporate them into their innovation processes. However, this finding strongly contrasts with the results of the research presented in this article.

Having considered it, we can assume that while foodstuff producers measure customer satisfaction, they do not measure end consumer satisfaction (since the majority of their customers are vendors who resell the products). The aforementioned scenario leads to a confusion of sorts: companies think the quality of their products is much better, as compared with the opinion of the consumers and, consequently, they tend to believe that customer (end consumer) satisfaction is much higher, as compared to what these consumers may actually think.

\section{Conclusions}

From the point of view of respondents/consumers, we can say that the quality of the food products is above average. On the other hand, it is evident that customers perceive certain imperfections that the foodstuff producers need to address. Most of these imperfections are related to quality (technical or moral). It is evident that the typical Czech consumer wants high technical quality of products for low prices, which is a very tough task, affected by several technical and financial factors. On the other hand, we need to ask ourselves whether manufacturers (or vendors) underestimate communication with customers by failing to explain what they pay for and why.

It is evident that a correlation exists between the problems with product quality and the ability (or, in this case, the lack thereof) of companies to conduct regular (every few days or weeks) and systematic surveys of customer satisfaction. The process of collection of this information is evidently insufficient. If it $i s$ collected, it is debatable whether or not 
the respective manufacturer has this information at their disposal. A manufacturer who does not have at their disposal the necessary information regarding customer satisfaction cannot increase and ensure product quality in the long run; this might be one of the reasons why the rating of product quality and overall customer satisfaction are not higher.

It seems that while foodstuff manufacturers do survey the satisfaction of their customers, they fail to survey the satisfaction of the end consumers. Having compared the findings of the two respective researches we discovered that the customers of foodstuff manufacturers who are not end consumers do not share the same opinion with the actual end consumers (due to various levels of familiarity and knowledge, origins of the products, the respective groups' goals etc.).

Therefore, it is recommended that companies focus on their end consumer and their satisfaction, even though it is a complicated and lengthy process (due to the distribution method used). Satisfaction of end consumers can be measured and evaluated with the use of the Internet or via interviews (upon an agreement with an intermediary) conducted in POS's where the products in question are purchased. Naturally, the use of the Internet is cheaper and faster. On the other hand, this method is more complicated in terms of methodology (particularly in terms of the selection of respondents and legitimacy of the results).

The research shows that a satisfied customer is one whose needs have been fulfilled. Hence, if a company wants to be successful (in terms of performance and competitiveness) it must be aware of the needs of its customers. Previous research projects show that numerous companies are falsely convinced that they know what their customers want and, consequently, they have no customer satisfaction survey systems in place. Unsatisfactory profits (performance) of these companies should serve as a warning to other companies.

On the other hand, it seems that customers can be convinced (at least partially) of the quality of a product - if the quality of a product improves, customers often tend to believe it has become even better than competing products (regardless of whether or not the competition has improved the quality of its product(s) as well). It may seem like a good idea to use marketing tools to convince customers of product quality, instead of asking them about their needs, expectations and satisfaction. However, this process is very expensive and its sustainability over longer periods of time is questionable.

\section{References}

Anderson, E. W., Fornell, C., Lehmann, D. R. (1994). Customer Satisfaction, Market Share, and Profitability: Findings from Sweden. Journal of Marketing, 58(3), 53-66.

DOI: $10.2307 / 1252310$.

Crosby, P. B. (1979). Quality is Free: The Art of Making Quality Certain. New York: McGraw Hill Custom Publishing.

Deming, W. E. (1982). Quality, Productivity, and Competitive Position. Cambridge, MA: Massachusetts Institute of Technology, Center for Advanced Engineering Study.

Gómez, M. I. et al. (2004). Customer Satisfaction and Retail Sales Performance: An Empirical Investigation. Journal of Retailing, 80(4), 265-278. DOI: 10.1016/j.jretai.2004.10.003.

Homburg, C. et al. (2005). Do Satisfied Customers Really Pay More? A Study of the Relationship between Customer Satisfaction and Willingness to Pay. Journal of Marketing, 69(2), 84-96. DOI: 10.1509/jmkg.69.2.84.60760. 
Oliver, R. L. (1980). A Cognitive Model of the Antecedents and Consequences of Satisfaction Decisions. Journal of Marketing Research, 17(4), 460. DOI: 10.2307/3150499.

Parasuraman, A., Zeithaml, V. A., Berry, L. L. (1985). A Conceptual Model of Service Quality and its Implications for Future Research. The Journal of Marketing, 49(4), 41-50. DOI: $10.2307 / 1251430$.

Suchánek, P. (2012). Kvalita a výkonnost podniků v cestovním ruchu - komparace s podniky potravinářského průmyslu (The Quality and Performance of Enterprises in Tourism An Comparison with Enterprises of Food Industry, in English) in Prague 8 VIII, Czech Hospitality and Tourism Papers. Hotelnictví, lázeňství, turismus. Prague: The Institute of Hospitality Management, 16/2012, 32-52.

Suchánek, P., Špalek, J. (2012). Quality and Performance of the Company in the Czech Republic. Acta universitatis agriculturae et silviculturae Mendelianae Brunensis, Brno: Mendel University in Brno, 60(4), 351-362. DOI: 10.11118/actaun201260040351.

Státní zemědělský intervenční fond (2011). Pravidla pro udělování národní značky KLASA. SZIF, Oddělení marketing. (The Rules for Awarding the KLASA National Mark of Quality. The State Agricultural Intervention Fund, Marketing Department, in English) Available at: http://www.eklasa.cz/filespace/content/pravidla_pro_udelovani_narodni_znacky_KLASA.pdf

Zamazalová, M. (2008). Spokojenost zákazníka. (Customer satisfaction, in English) Acta Oeconomica Pragensia, 16(4), 76-82. DOI: 10.18267/j.aop.135.

Zeithaml, V. A. (1988). Consumer Perceptions of Price, Quality, and Value: A Means-End Model and Synthesis of Evidence. Journal of Marketing, 52(3), 2-22. DOI: 10.2307/1251446. 